\title{
Bioethical Issues in the Management of Gender Dysphoria
}

George R. Brown, MD

Wright State University

Follow this and additional works at: https://jdc.jefferson.edu/jeffjpsychiatry

Part of the Psychiatry Commons

Let us know how access to this document benefits you

\section{Recommended Citation}

Brown, MD, George R. (1988) "Bioethical Issues in the Management of Gender Dysphoria," Jefferson Journal of Psychiatry. Vol. 6 : Iss. 1 , Article 6.

DOI: https://doi.org/10.29046/JJP.006.1.004

Available at: https://jdc.jefferson.edu/jeffjpsychiatry/vol6/iss $1 / 6$

This Article is brought to you for free and open access by the Jefferson Digital Commons. The Jefferson Digital Commons is a service of Thomas Jefferson University's Center for Teaching and Learning (CTL). The Commons is a showcase for Jefferson books and journals, peer-reviewed scholarly publications, unique historical collections from the University archives, and teaching tools. The Jefferson Digital Commons allows researchers and interested readers anywhere in the world to learn about and keep up to date with Jefferson scholarship. This article has been accepted for inclusion in Jefferson Journal of Psychiatry by an authorized administrator of the Jefferson Digital Commons. For more information, please contact: JeffersonDigitalCommons@jefferson.edu. 


\title{
Bioethical Issues in the Management of Gender Dysphoria
}

\author{
George R. Brown, M.D.
}

\section{INTRODUCTION}

The term "gender dysphoria" (1) describes a heterogeneous group of individuals who express varying degrees of dissatisfaction with their anatomic gender (hence "gender dysphoria"), and the desire to possess the secondary sexual characteristics of the opposite sex. Only a minority of these patients can be considered on the extreme end of a spectrum of subjective dissatisfaction with assigned anatomy and societally sanctioned gender role (i.e., "transsexual"). The number of such patients presenting to psychiatric clinics has greatly increased subsequent to the 1966 publication of Harry Benjamin's seminal work, The Transsexual Phenomenon (2), and extensive media coverage of individual cases, e.g., Christine Jorgensen, Jan Morris, and Renee Richards, MD.

While the term "transsexualism" was introduced in 1949 (3), its use was not standardized until its initial appearance in DSM-III in 1980 (4). DSM-III-R (5) contains significant revisions in the clinical definition of transsexualism and includes a new diagnostic category for patients who are gender dysphoric but do not meet the restrictive criteria for transsexualism: gender identity disorder of adolescence or adulthood, nontranssexual type. It is apparent from this evolution of nosologic thought that not all patients who present with gender dysphoria and the chief complaint, "I want a sex change operation," are transsexual. While the incidence of male-to-female transsexualism is conservatively estimated at 1:37,000 anatomic males (6), the prevalence of severe gender dysphoric conditions is believed to be at least ten times higher (7). This is based on the diagnoses of patients who are seen at approximately 40 specialized gender identity clinics in North America (Table 1).

The probability of obtaining sex reassignment surgery (SRS), i.e. surgical alteration of existing genital structures to anatomically approximate those of the other sex, morphologically and functionally, through an established gender clinic ranges between $15 \%$ and $27 \%$, depending on age, sex, diagnoses, and other factors (8). It is estimated that over 11,000 SRS procedures have been performed in the U.S. alone (9), with another 60,000 U.S. citizens considering themselves to be valid candidates for such procedures (10). Clinical psychiatrists are likely to evaluate one or more patients in their practices for whom gender identity disorders are the primary diagnostic consideration, even in such "unlikely" environments as the military service (11).

Dr. Brown is a fourth year resident in psychiatry at Wright State University, Dayton, Ohio. 
TABLE 1.

\section{Differential Diagnosis of Gender Dysphoria}

Primary and Secondary 'Transsexualism

Transvestism with depression or regression

Schizophrenia with gender identity disturbance

Effeminate homosexuality with adjustment disorder

Homophobic homosexuality

Career female impersonators

Borderline Personality Disorder with severe gender identity issues

Body Dysmorphic Disorder

Gender Identity Disorder, nontranssexual type

Atypical Gender Identity Disorder

Ambiguous gender identity adaptation

Malingering

The Harry Benjamin International Gender Dysphoria Association (HBIGDA) was founded in 1979 by a group of psychiatrists, surgeons, psychologists, endocrinologists, and social workers who are actively involved in gender identity research and the care of gender dysphoric patients. This author is the only psychiatric resident member of the organization and has had the opportunity to collaborate with many of the founding members. The HBIGDA has recognized the numerous bioethical and medicolegal issues surrounding the care of gender dysphoric persons, and pioneered formal Standards of Care in the late 1970's (12). These original standards have since been revised and were made available to the professional community in 1985 (10).

My experience at the Case Western Reserve Gender Identity Clinic and clinical evaluation of 17 severely gender dysphoric patients in four cities (Rochester, Cleveland, Cincinnati, and Dayton) over the previous five years prompted an examination of the bioethical issues encountered in the management of such patients. All patients evaluated were anatomic males with the expressed wish for SRS. Three patients had already undergone SRS, one was accepted for SRS and had received cross-gender hormonal treatments for over a year, five others had self-administered cross-gender hormones obtained illicitly, and the remaining eight were at various stages of the evaluation process.

The discussion that follows is not to serve as a sterile debate of issues, but rather as an attempt to familiarize the reader with the difficult ethical concerns inherent in caring for individuals who desperately seek reassignment.

\section{THE PHYSICIAN'S DILEMMA}

The availability of sex reassignment surgery as an intervention in the overall management of transsexualism raises a number of bioethical issues for physicians. The term "bioethical," albeit accurate, does not begin to describe 
the intense reactions experienced by those of us who are asked to, or choose to, ponder the question of gender transmutation. This is evidenced in published statements by respected clinicians such as Lawrence Kubie:

This passing fad for what is miscalled 'transsexualism' has led to the most tragic betrayal of human expectation in which medicine and modern endocrinology and surgery have been engaged (13).

What the late Dr. Kubie referred to as a "passing fad" has anything but passed us by. Gender dysphoric patients continue to present to gender identity clinics and private practitioners a critical need for psychiatric care. These patients engender a sense of desperateness and urgency unparalleled in most other areas of psychiatry. Their lives become a "frantic preoccupation" (14) with obtaining cross-gender hormones and SRS, often to the exclusion of progressing through school, building relationships, or maintaining employment.

Physician response may be to ally with the patient in his all-encompassing quest for somatic treatment, leading to prescription of hormones and referral for SRS. Alternatively, physicians may be extremely reticent to entertain such treatment requests, erecting the defensive facades of "do no harm" and "never deliberately remove a healthy organ." This tack may be represented in Kavanaugh and Volkan's pejorative description of SRS as "a new type of psychosurgery" (15).

Physicians are faced with a complex dilemma that revolves around two central questions: What constitutes suffering in the gender dysphoric patient, and what are the ethically and morally viable interventions available to relieve suffering in these patients? The Oath of Hippocrates (16) reminds us that the relief of suffering is the quintessential task of all of medicine. The gender dysphoric patient relates his subjective experience of suffering very clearly, but what the physician may do to relieve it is unclear. J. Cassell, an internist, warns us:

The most well-intentioned and best-trained physicians may cause suffering inadvertently in the course of treating disease and may fail to relieve suffering when that might otherwise be possible (17).

Psychoanalytic theory emphasizes that one's "highly prized sexual organs" (18) are cathected with a great amount of libidinal energy. A male who pleads with us to castrate him and amputate his penis may arouse, on an unconscious level, significant castration anxiety. Lothstein described such anxiety in a male anesthesiologist who nearly suffocated a male-to-female transsexual patient during SRS (19). The capacity to fully empathize with such a patient may be rarely, if ever, found in non-gender dysphoric individuals even if they are sympathetic to the plight of the transsexual. Significant countertransference issues are certainly evident in comments published by two surgeons who have 
performed SRS:

Our big problem is to differentiate the dissatisfied old homosexuals who just want a new thrill from the true transsexuals.

Some of the people who apply for this kind of operation are just flaming faggots. After you have talked to a few of them there is no problem in distinguishing among the transvestite, homosexual, and transsexual (20).

The inability to fully empathize is a potential obstacle to objective medical care and unbiased, meaningful outcome studies in the field of gender dysphoria. This, in turn, contributes to the difficulty in addressing the ethical questions.

Psychiatrists have examined the legitimacy of recommending a radical surgical intervention for a disorder considered, but not established, to be primarily psychiatric in origin (21). What interventions clash with one's identity as a psychiatrist? Where does one turn for guidance when faced with actual clinical situations with desperate, gender dysphoric individuals?

The decision-making process may be enlightened by a review of the Hippocratic Oath:

I will follow that system of regimen which, according to my ability and judgment, I consider for the benefit of my patients, and abstain from whatever is deleterious and mischievous (16).

In this instance the Oath appears to support an approach to gender dysphoria that may ethically include SRS if it is considered by the practitioner and patient alike to be of potential benefit. Conversely, the same Oath excerpt may be used to condemn SRS as harmful, mutilative, and deleterious. The scientific literature may serve as an additional source of information to address the ethics of an intervention. For example, if a surgical intervention is shown to be useless or harmful in replicated, controlled studies, it is likely that physicians would consider continued use of such a procedure unethical. In spite of the fact that SRS has been performed for 24 years in the United States, it is still unknown whether it is the most effective form of treatment for transsexualism (22). Clinical decisions must be made in the absence of definitive, prospective, long-term studies of the effectiveness of SRS compared to nonsurgical treatment modalities (23). Decisions must also be made with the awareness that the psychiatrist shares the "moral responsibility for that decision (i.e., whether or not to refer for SRS) with the surgeon who accepts that recommendation" (10).

The determination by some physicians to consider SRS an ethical therapeutic adjunct is largely a matter of personally witnessing individuals as they undergo the painful process of gender reorientation, which may include SRS and hormonal treatments. Numerous authors have reached the conclusion that SRS can contribute to the relief of suffering, enable better psychosocial adjustment, and impart a sense of well-being to these distressed individuals 
$(9,22,24,25)$. Others have disputed these claims, noting that positive outcome studies are seriously flawed by researcher bias and the lack of control groups $(23,26)$. A comprehensive review of the literature pertaining to gender dysphoria since 1980 conducted by the author ( 265 articles by 174 different first authors) revealed that quantitatively more articles are supportive of SRS for carefully selected patients. This, of course, does not necessarily represent consensus, and may only demonstrate that those who support SRS are more prolific.

Lacking definitive studies, anecdotes and personal experiences supportive of SRS as a viable treatment modality are bolstered by the published consensus statement of the HBIGDA that "hormonal and surgical sex reassignment has been demonstrated to be a rehabilitative, or habilitative, experience for properly selected adult patients" (10). As noted, all experts in this field are not in agreement that this has been adequately demonstrated.

While we can agree that man's dignity transcends his biological condition, the radical alteration of a patient's "natural" physical condition because he requests it, will continue to be an ethical issue as we search for ways to enable gender dysphoric patients to reduce the dissonance between their anatomy and their sense of self.

\section{SELECTION OF PATIENTS}

If one concurs with the HBIGDA in the opinion that SRS can, in fact, contribute to the relief of suffering and enable better psychosocial adjustment, another ethical dilemma immediately becomes apparent: Which gender dysphoric patients should be approved for surgery? In our calculated attempts to relieve suffering, the misapplication of irreversible genital surgery is associated with disastrous consequences including depression, psychosis, suicide and a total loss of dignity and self-esteem (27-30). While SRS cannot truly be credited with "creating" a woman out of a man (and certainly not vice versa), it can be blamed for creating an anatomically distinct third category of "other," i.e. the postoperative transsexual, who may feel even more alienated and biologically incongruent than before SRS (31).

As we struggle with these issues in the context of facing disturbed gender dysphoric patients who are absolutely convinced that only hormones and surgery will end their plight, we must keep several concepts in mind:

1. The request for SRS is the solution the patient has presented to us. What then, is the nature of the problem in a given patient?

2. Radical surgical interventions cannot alter an Axis II diagnosis of personality disorder, conditions diagnosed in 50-70\% of applicants for SRS (32).

3. Surgery alone is not curative or rehabilitative. SRS is only one component of a multidisciplinary approach to the rehabilitation process and 
should be viewed as confirmation of what the patient has already achieved with our assistance $(22,33,34)$.

It is clear then, that for any patient referred for SRS this step should be an anticlimactic conclusion of what has already been achieved, prompting Edgerton, a prominent SRS surgeon, to consider this "sex confirmation surgery" (22).

Sadly, just as resourceful patients are able to obtain hormones illicitly, they can also obtain some forms of SRS from surgeons unaffiliated with established gender clinics in the U.S. and abroad (35). Many of these individuals have been subjected to "inferior surgical techniques and preoperative selection procedures" with outcomes anecdotally reported as "horrifying" (36). One such patient awoke from anesthesia to find that her newly created clitoris had been placed inferiorly to her urethra (37). Since the publication of the formal Standards of Care for the evaluation and treatment of gender dysphoric individuals $(10,12)$, there would appear to be little room for the "chop shop" or "bargain basement" approach to SRS (34). Civil liability could be incurred by a surgeon in cases where the patient is dissatisfied with cosmetic and/or functional outcomes on the grounds that negligence occurred in preoperative evaluation. The case against the surgeon would be strengthened if the evaluation was brief and/or inconsistent with the Standards of Care, which clearly state that a minimum of two qualified mental health professionals must thoroughly evaluate the patient longitudinally, prior to recommendations for SRS. Criminal charges could be filed as well, with prosecution based on the premeditated "act of intentionally mutilating a person's body or injuring it so as to deprive him of a limb or any organ of the body," i.e. mayhem $(7,38)$.

The probability of a poor outcome, including post-operative suicide, is believed to be increased in patients who receive SRS without proper evaluation and lengthy preoperative preparation, including one to two years minimum of successful cross-gender living $(9,19,32,39,40)$. This is likely to be a result of operating on individuals who:

1. Impulsively request SRS after a major loss (concurrent diagnosis of complicated bereavement, adjustment disorder with depressed mood, major depression) (32).

2. Have a primary Axis I diagnosis other than transsexualism. For example, transvestism with marked regression under stress (41) or other disorders listed in Table 1.

3. Have a personality disorder that includes a high degree of impulsivity (borderline, histrionic, antisocial).

Hundreds of patients choose to work with established gender clinics, which number about forty in North America $(7,10)$. Procedures are offered only to those patients who complete a multistep program, which by design includes a number of obstacles. For example, patients are required to live and work 
full-time in the cross-gender role for a minimum of one or two years, engage in psychotherapy for at least a year, maintain a responsible payment record with the psychotherapist, get divorced if married (SRS will not be performed on married patients for legal reasons), and take cross-gender hormones for at least one year if medically tolerable $(7,32)$. Negotiation of these obstacles may result in enhanced ego strength mediated by successful psychotherapy and selection of nonsurgical alternatives, e.g. hormonal treatment alone or long-term group psychotherapy (42). If the patient is able to collaborate successfully with the gender clinic's staff in meeting these requirements and still desires SRS, referral is made for those who, in the opinion and judgment of the clinic staff, can profit from it by establishing a productive, socially acceptable lifestyle (34).

The bias inherent in this judgement is indisputable and varies among clinics. For example, some would consider prostitution by a reassigned maleto-female patient an acceptable professional outcome if the patient is selfsupporting, not receiving public assistance, and satisfied with this vocational choice. Others would consider this objectionable and unacceptable and would deny referral for SRS if this was known to be the patient's long-range career goal.

Patients considered "ideal" for referral (9) are those Fleming and Feinbloom have called the "psychologically healthy transsexuals" (43). They are the patients who do not seek to destroy or condemn the "old" self, but rather integrate earlier experiences into the "new" transformed self. Table 2 summarizes some of the features of patients considered acceptable as candidates for SRS in contrast to features associated with high risk or unacceptable applicants (9). Most of these parameters have been derived empirically from over two decades of surgical and psychiatric experience with gender dysphoric patients.

In addition to the features listed in Table 2 under "poor candidates," there are some relative contraindications to offering SRS that should be considered in the overall evaluation process:

1. Mental retardation. Grossly subnormal intellectual functioning may be incompatible with informed consent regarding the consequences of SRS and its irreversibility.

2. Past history of psychiatric illness such as schizophrenia, bipolar illness. A diagnosis of thought or affective disorder years before a request for SRS is not necessarily incompatible with good outcome $(10,34)$.

3. Poor medical condition, e.g. inability to tolerate hormonal treatment, or other physical disorders that would place the patient at risk for major surgical procedures. (Few conditions exist that would be absolute contraindications, as modern anesthesia practice enables surgery to be performed safely on most individuals.)

The characteristics of acceptable candidates for SRS continue to undergo revision as more data becomes available (40). Just as it is impossible to predict with certainty which young, first-admission manic patients will relapse in the 
TABLE 2.

Categorization of Candidates for Sex Reassignment Surgery

\begin{tabular}{lc}
\hline \multicolumn{1}{c}{ "Good" Candidates } & "Poor" Candidates \\
\hline - Lifelong cross-gender identification & - Absence of characteristics listed under \\
- Inability to adapt/to live in assigned & "good" candidates \\
biologically congruent gender role & -Active or recent thought disorder or \\
- Capacity to "pass" effortlessly and & affective disorder \\
convincingly in society & - Exclusively fetishistic use of cross- \\
- Not considered a fetishistic cross- & dressing \\
dresser & - Recent identifiable major loss precipi- \\
- First heterosexual experience, if pres- & tating impulsive request for hormones \\
ent, was in early adulthood rather & and SRS \\
than adolescence & - History of significant antisocial behav- \\
- Some college education & - Multiple suicide gestures and at- \\
- Demonstration of "stability"-hold- & tempts, including genital self-mutila- \\
ing same job for years, long-term rela- & tion \\
tionships, etc. & -Active substance dependence \\
- Willingness to accept and actively en- & - Lack of social and/or financial sup- \\
gage in psychotherapy pre- and post- & port system \\
operatively & - Lack of funds to finance medical care \\
- Presence of adequate social and/or & and postoperative complications \\
family support systems & - Delusional/magical expectations of \\
- Completion of a program at a recog- & surgery \\
nized gender identity clinic, including & - Circumvention of gender identity clin- \\
two years of successful living/working & ics and procedures, e.g. illicitly obtain- \\
in cross-gender role & ing hormones \\
-At least one year of medically super- & - Significant resistance of therapist af- \\
vised hormonal treatment & ter long-term psychotherapy relation- \\
- Absence of any characteristics of & ship to refer for SRS even though ther- \\
"poor" candidates & apist has referred others \\
- Therapist comfort in referral after & \\
long-term psychotherapy relationship & \\
\hline &
\end{tabular}

future, it is also not possible to predict which gender dysphoric patients will have an overall positive or negative post-surgical adjustment. Many believe, however, that patient compliance with treatment coordinated by an established gender identity clinic and demonstrated success in the cross-gender role for one to three years may be the most valuable selection criteria and prognosticators $(9,33,34,39)$.

\section{SUICIDE AND SURGERY}

The dictum, "above all, do no harm" takes on a particular significance when any psychiatric patient commits suicide. Ethical and moral questions become more pressing as we retrospectively examine our relationship with a patient who has suffered this outcome. What could we have done, if anything, to prevent such a tragic occurence? Along with psychotic decompensation (44), 
post-operative suicide is often cited as the most compelling reason to disallow SRS as a treatment modality $(23,45)$. Thorough reviews of the numerous outcome reports are provided by Lothstein (26) and Lundstrom, et al. (40). The suicide rate in post-operative transsexuals at 11 centers has been reported as $2.1 \%$ of those who received this procedure, based on follow-up durations of 0.3 to 19 years (40). Suicide attempts may be more frequent in gender dysphoric patients who are refused SRS than in those who receive it. In Lundstrom's study of 30 transsexuals not accepted for SRS, one committed suicide and $59 \%$ of the remainder attempted it at least once (46). Unfortunately, no studies addressing suicide and SRS have separated patients into groups with and without personality disorders (23). For example, the incidence of suicide attempts in patients with severe borderline personality disorder is high, irrespective of gender pathology, Therefore, data obtained from a group of gender dysphoric patients heterogeneous for borderline personality disorder is difficult to interpret.

How long after SRS can suicide be reasonably considered a post-operative complication? If a patient has a poor cosmetic and functional outcome, develops a severe depression in the weeks after surgery and shortly thereafter commits suicide, many clinicians would consider this temporal relationship more than coincidence (19). The fact that Ruth Shumaker, coauthor of a poignant and insightful paper on her intrapsychic life as a transsexual (47), committed suicide seven years after SRS (28) cannot be definitively attributed to her treatment. An alternative interpretation is that SRS enabled the patient to live up to seven years longer than she may have otherwise.

If we are trying to "do no harm," do we harm less by operating more, or harm more by operating less? The $2.1 \%$ suicide rate previously mentioned prompted Pauly to state emphatically: "I feel it is not justified to conclude that surgery carries a higher risk of suicide or attempted suicide than does refusal" (48).

Just as with classic existential issues, the answers to the ethical questions concerning SRS may never be forthcoming. It would be comfortable if there were well-designed, controlled, prospective studies with large numbers of patients to help us address these issues (23). As these are lacking, we may be left with the same ethical and moral dilemmas with little data to fashion our clinical opinions and much confusion to fuel our own dysphoria.

\section{CONCLUSION}

Clinicians faced with the evaluation and treatment of gender dysphoric individuals are plagued with difficult bioethical issues. While we, as a medical community, have no qualms about genital surgery for inborn biological errors, e.g. ambiguous genitalia conditions and pseudohermaphroditism (49), the same detached approach has not been applied to altering the anatomy of transsexuals. Since we have found no consistent biological (hormonal, genetic, anatomic) marker or defect, the etiology is presumed to be psychogenic/developmental by 
default, and the appropriateness of radical surgical treatment for functional disorder is called into question (50). "Above all, do no harm" is to be heeded with special care by mental health professionals facing both a lack of knowledge and an abundance of ethical dilemmas. This could, and should, lead to the restriction of SRS to centers involved in a multiuniversity research project aimed at addressing the relevant extant clinical questions $(22,32)$.

In spite of proclamations that nothing else holds promise for the treatment of transsexualism other than SRS (25), less invasive interventions have been shown to be useful for some patients, e.g. expressive group psychotherapy (42), hormonal treatment in conjunction with psychotherapy (51), and behavior therapy (52). Ethical dilemmas related to denial of SRS continue, such as the reported increased rate of suicide attempts and withholding treatment considered by some experts to be life saving. Controlled, prospective studies comparing treatment modalities are needed.

Is SRS then, an elective cosmetic procedure as most insurance carriers claim? Is it the treatment of choice for selected gender dysphoric patients, or a well-intentioned mutilation tantamount to mayhem? There are no generalizations to adhere to, no convenient "rules-of-thumb." But there are patients with severe, pervasive disturbances in their sense of self who seek out those health care professionals who are willing to confront their own ethical and moral standards in an attempt to provide appropriate care. Unaddressed negative countertransference responses to gender dysphoric patients, who are often manipulative and driven, may interfere with clinical decision-making and contribute to the suffering these patients endure (53).

\section{ACKNOWLEDGEMENTS}

The author wishes to thank the staff of the Case Western University Gender Identity Clinic for their guidance; Leslie Lothstein, Ph.D., Director, Department of Psychology, The Institute of Living, Hartford, Connecticut for his intellectual stimulation; Sandra A. Dinwoodie for technical support and preparation of the manuscript.

\section{REFERENCES}

1. Fisk N: Gender dysphoria syndrome-The how, what, and why of a disease, in Proceedings of the Second Interdisciplinary Symposium on Gender Dysphoria Syndrome. Edited by Laub D, Gandy P. Palo Alto, Calif., Stanford University Press, 1973

2. Benjamin H: The Transsexual Phenomenon. New York, Julian Press, 1966

3. Cauldwell DO: Psychopathia transsexualis. Sexology 1949; 16:274-280

4. American Psychiatric Association: Diagnostic and Statistical Manual of Mental Disorders, Third Edition. Washington, DC, American Psychiatric Association, 1980 
29. Meyer J, Reter D: Sex reassignment. Arch Gen Psychiatry 1979; 36:1010-1015

30. Money J, Wolff G: Sex reassignment: male-to-female-to-male. Arch Sex Behav 1973; 2:245-250

31. Blank R: The partial transsexual. Amer J Psychother 1981; 35:107-112

32. Levine SB, Lothstein LM: Transsexualism or the gender dysphoria syndromes. J Sex Marit Ther 1981; 7:85-113

33. Dushoff IM: Economic, psychologic, and social rehabilitation of male and female transsexuals, in Proceedings of the Second Interdisciplinary Symposium on Gender Dysphoria Syndrome. Edited by Laub DR, Gandy P. Palo Alto, Stanford University Press, 1973

34. Fisk N: Five spectacular results. Arch Sex Behav 1978; 7:351-369

35. Gottlieb A: Three atypical results. Arch Sex Behav 1978; 7:371-375

36. Belli M: Transsexual surgery: a new tort? JAMA 1978; 239:2143-2148

37. Laub D: Sex reconfirmation surgery. Presented at the 10th International Symposium on Gender Dysphoria, Amsterdam, June 9-12, 1987

38. Webster's New Twentieth Century Dictionary, Second Edition, William Collins and World Publishing Co., 1977

39. Edgerton M, Langman M, Schmidt J, et al: Psychological considerations of gender reassignment surgery. Clin Plast Surg 1982; 9:355-366

40. Lundstrom B, Pauly I, Walinder J: Outcome of sex reassignment surgery. Acta Psychiatr Scand 1984; 70:289-294

41. Wise TN, Meyer JK: Transvestites who become gender dysphoric. Arch Sex Behav $1980 ; 9: 323-337$

42. Keller AC, Althof SE, Lothstein LM: Group therapy with gender identity patients-a four year study. Amer J Psychother 1982; 36:223-228

43. Fleming M, Feinbloom D: Similarities in becoming: transsexuals and adolescents. Adolescence 1984; 19:729-748

44. Van Putten T, Fawzy FI: Sex conversion surgery in a man with severe gender dysphoria. Arch Gen Psychiatry 1976; 33:751-753

45. Sorensen T: A follow-up study of operated transsexual males. Acta Psychiatr Scand $1981 ; 63: 486-503$

46. Lundstrom B: A follow-up study of 30 transsexuals not accepted for sex-reassignment. Presented at The Sixth International Gender Dysphoria Symposium, San Diego, 1979

47. Levine SB, Shumaker RE: Increasingly Ruth: toward understanding sex reassignment. Arch Sex Behav 1983; 12:247-261

48. Pauly IB: Outcome of sex reassignment surgery for transsexuals. Aust New Zea J Psychiatry $1981 ; 15: 45-51$

49. Money J, Devore H, Norman B: Gender identity and gender transposition: longitudinal outcome study of 32 male hermaphrodites assigned as girls. J Sex Marit Ther $1986 ; 12: 165-181$

50. Lothstein LM: Theories of transsexualism, in Sexuality in Medicine. Vol I. Edited by Shelp E. Dordrecht, Holland, D. Reidel, 1987

51. Leavitt F, Berger J, Hoeppner J, et al: Presurgical adjustment in male transsexuals with and without hormonal treatment. J Nerv Ment Dis 1980; 168:693-697

52. Shtasel TF: Behavioral treatment of transsexualism: a case report. J Sex Marit Ther $1979 ; 5: 362-367$

53. Lothstein LM: Countertransference reactions to gender dysphoric patients: implications for psychotherapy. Psychother Theory Res Prac 1977; 24:21-31 